\title{
GROWTH OF NANNOCHLORIS ALGAE IN THE PRESENCE OF MICROWAVES (CONTINUOUS REACTOR)
}

\author{
I. Calinescu ${ }^{1}$, A. Vintila ${ }^{1,2}$, A. Diacon ${ }^{1}$, M. Vinatoru ${ }^{1}$, P. Chipurici ${ }^{1}$, Ana-Maria Galan ${ }^{2}$, \\ Sanda Velea ${ }^{2}$
}

1 Faculty of Applied Chemistry and Material Science, University "Politehnica » of Bucharest, 1-7 Gh. Polizu, Bucharest, 011061, Romania

${ }^{2}$ National Institute for Research \& Development in Chemistry and Petrochemistry ICECHIM, 202 Spl. Independentei, 060021, Bucharest, Romania

Ioan.calinescu@upb.ro

Keywords: microwave, bioeffect, nannochloris, PUFA, carotenoids

\begin{abstract}
Algae are very effective in capturing the sun's energy, carbon dioxide from the atmosphere, and nutrients to turn them into useful substances. Certain algae contain significant amounts of unsaturated oils but also carotenoids. The commercial value of these compounds can be greatly increased by increasing the degree of unsaturation of oils and the carotenoid concentration. One of the possibilities to alter the growth rate of algae and metabolite composition is microwave irradiation. By microwave-controlled irradiation of the nutrient and algae flux, which is recirculated through the photobioreactor and through a glass reactor located in a TE-type monomod cavity, the algal oil content increased and the change in oil fraction composition was important. Significantly increased the concentration of polyunsaturated acids with 16 and 18 carbon atoms. As far as carotenoids are concerned, the algae nannochloris has a higher carotenoid content over many known vegetables holding carotene or lycopene (carrots or tomatoes). Besides oil increasing microwave treatment produced a significant increase in carotenoid content of algae. They can be extracted together with omega-3-rich algal oil and are the basis of very valuable dietary supplements.
\end{abstract}

\section{Introduction}

Algae are very effective in capturing the sun's energy, carbon dioxide from the atmosphere, and nutrients to turn them into useful substances (carbohydrates, oils, proteins, etc.). Besides the main metabolites, there are also secondary metabolites, such as carotenoids (astaxanthin, $\beta$-carotene, lutein, lycopene, and canthaxanthin [1].

Both major and compounds existing in small amounts in algae are useful. Oils and carbohydrates could provide biofuels, proteins can get products with nutritional value and from carotenoids can be prepared food supplements. Obtaining biofuel from algae has not yet proved to be economically viable $[2,3]$. A much higher interest might be getting food supplements from algae. To increase their value as ingredients for food supplements, algal oils should have a higher degree of unsaturation (rich in omega 3) and an increased carotenoid content to be an important additional benefit in over all processing of algae.

There are studies that refer to the influence of environmental factors on algae composition [2], but the microwave influence on algae growth, especially algal metabolites composition change is very poor studied.

One of the first descriptions of microwave effect on algae is that of Hamid and Badour in 1973[4]. The authors study the effect of microwaves on algae at high temperatures (50 to $100{ }^{\circ} \mathrm{C}$ ) resulting in proteolysis and complete failure of the alga to photosynthesize and 
grow, and at $35-40^{\circ} \mathrm{C}$, exerted a stimulating effect on photosynthesis and subsequent algal growth as compared to conventional heating within the same temperature range.

Another important factor in stimulating algal growth is the wavelength of electromagnetic radiation, thus $7.1 \mathrm{~mm}$ wavelength (exposure for $30 \mathrm{~min}$ at $2.2 \mathrm{~mW} / \mathrm{cm}^{2}$ ) enhanced the growth of a blue-green algae Spirulina platensis by $50 \%$, whereas $8.34 \mathrm{~mm}$ wavelength produced no changes compared with sham control [Tambiev et al., 1989 in [5]].

In this paper, besides the experiments for the activation of algal growth in discontinuous reactors [6] additional work was conducted in a continuous photobioreactor. The goal was checking not only the growth of microalgae but also their content in polyunsaturated oil and in carotenoids.

\section{Experimental section}

\section{Microalgae Data}

Nannochloris sp. 424-1 is a strain deposited under the number CCAP 251/10 in the Culture Collection of Algae and Protozoa (CCAP) at the Scottish Marine Institute, Aryll, UK. The strain was obtained from a wild strain by mutation-selection, after cultivation on media with metronidazole [7].

\section{Culture Medium}

The culture medium for Nannochloris $s p$. was Zarrouk medium, with the following composition $(\mathrm{g} / \mathrm{L}) 16.8 \mathrm{NaHCO}_{3}, 0.5 \mathrm{~K}_{2} \mathrm{HPO}_{4}, 2.5 \mathrm{NaNO}_{3}, 1.0 \quad \mathrm{~K}_{2} \mathrm{SO}_{4}, 1.0 \mathrm{NaCl}, 0.2$ $\mathrm{MgSO}_{4} .7 \mathrm{H}_{2} \mathrm{O}, 0.04 \mathrm{CaCl}_{2} .2 \mathrm{H}_{2} \mathrm{O}, 1 \mathrm{~mL} / \mathrm{L}$ of trace metal solution, and $5 \mathrm{~mL} / \mathrm{L}$ of chelated iron.

\section{Cultivation Conditions}

Microalgae were cultivated into a Biostat PBR 2S photobioreactor (a 3L volumetric type with a photosynthesis module), the photobioreactor being connected in series with the Miniflow 200SS microwave system. Microwave treatment was performed in a $25 \mathrm{~mL}$ volumetric glass coil mounted in the TE monomod cavity.

To perform each experiment, 0.3 L inoculum Nannochloris sp and 2.7 L Zarrouk growth medium were used respectively. Cultivation was carried out under photoautotrophic conditions: cultivation temperature $28^{\circ} \mathrm{C}$, continuous illumination $85 \mu \mathrm{mol} /\left(\mathrm{m}^{2} * \mathrm{~s}\right)$, continuous aeration with synthetic air mixture with $7 \% \mathrm{CO} 2(\mathrm{v} / \mathrm{v})$. All cultures were treated with microwave the day after inoculation. The culture was recirculated in the photoreactor using a pump flow rate of $0.0217 \mathrm{~L} / \mathrm{s}$.

\subsection{Cell Counting}

The algal cultures cell density was determined by direct cell counting daily by using a Thoma Hemocytometer [8]. The data obtained was reported as cell per mL.

\subsection{Biomass assay}

The quantity of the algal biomass obtained per $\mathrm{mL}$ of sample was determined by measuring the dry weight. The algal suspension was centrifuged at $8000 \mathrm{rpm}$ for 10 minutes using a Rotina 380R centrifuge from Hettich Zentrifugen. The biomass obtained was washed two times with distilled water and after that the biomass obtained was dried in the oven at $105^{\circ} \mathrm{C}$ for $1 \mathrm{~h}$ and then placed in vacuum desiccant for 30 minutes. The sample was weighed and then introduced in the oven for 30 minutes. The procedure was repeated until the weight of the sample was constant. For the determination and characterization of the oil content of the lipid fraction of the microalgae, an own method, as described in [9] was used. 


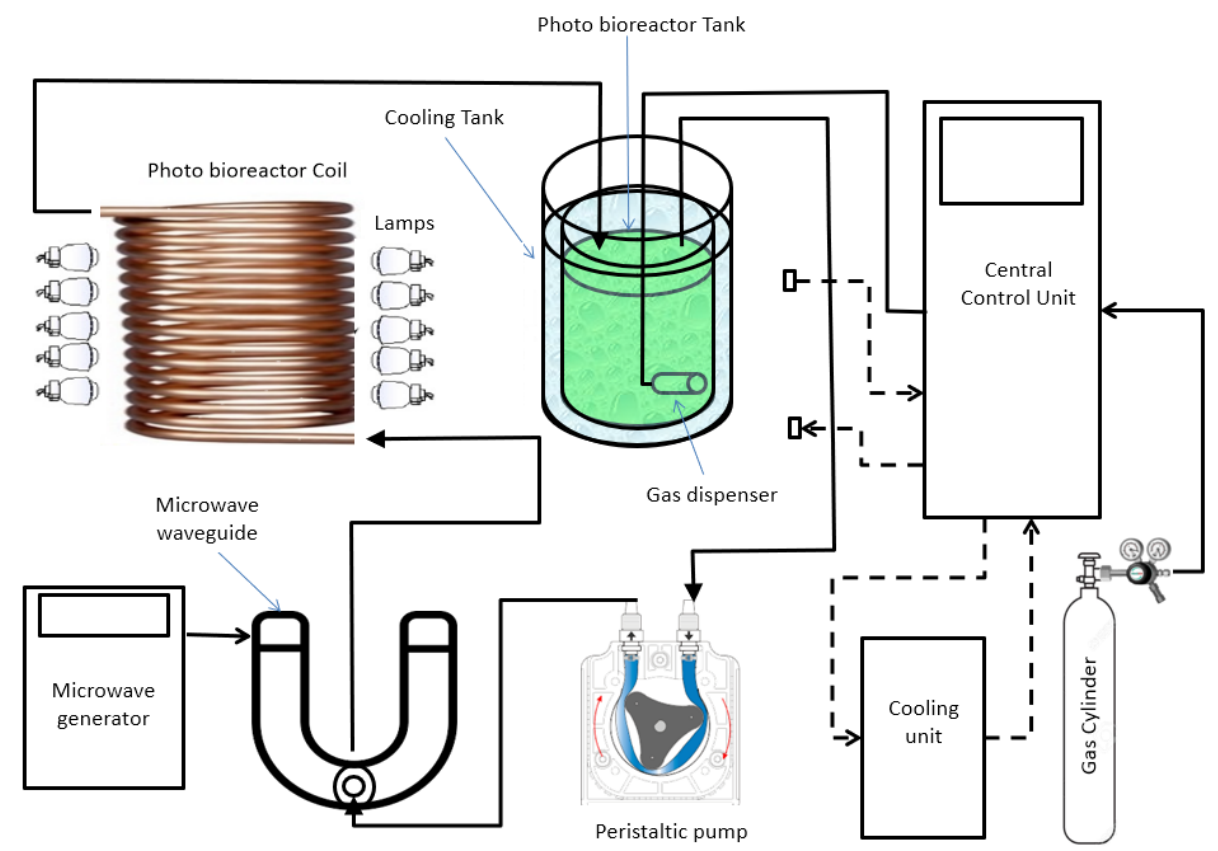

Fig. 1. Setup used for ultrasound assisted growing of algae

To determine the percentage of oil (transesterifiable lipids - free fatty acids and triglycerides) available in dry biomass. Equation 2 was used:

$\%$ oil in dry biomass $=\frac{C_{\text {esters }} \cdot \text { Vol }_{\text {esters }}}{\text { Weight }_{\text {dry biomass }}}$ where:

$\mathrm{C}_{\text {esters }}=$ the concentration of methyl esters of fatty acids obtained by GC-MS analysis $[\mathrm{g} / \mathrm{mL}]$;

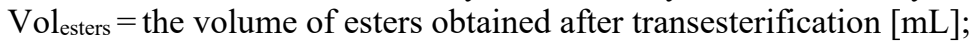

Weight $_{\text {dry biomass }}=$ the weight of dry biomass $[\mathrm{g}]$.

\subsection{Algal pigments determination}

The chlorophyll and carotenoids concentration was determined by UV-Vis spectroscopy in accordance with standard protocols [10]. The determination involved the extraction of 0.25 $\mathrm{g}$ of dried algal biomass with $10 \mathrm{~mL}$ of ethanol (95\%) (1:40 weight: volume ratio) at $55^{\circ} \mathrm{C}$ using an ultrasonic probe Hielscher UP200St (equipped with a titanium probe of $13 \mathrm{~mm}$ using $60 \%$ amplitude and $5 \mathrm{~s}$ on, $5 \mathrm{~s}$ off operating conditions) and a magnetic stirrer set for $800 \mathrm{rpm}$. The extract was centrifuged after $1 \mathrm{~h}$ of extraction and diluted with ethanol. The UV-Vis absorption spectra were registered using an Able Jasco V-550 spectrophotometer. The equations used to quantify the chlorophyll $\mathrm{a}$, chlorophyll $\mathrm{b}$ and beta-carotene content were:

$[\text { Chl a }]_{\frac{m g}{L}}=13,36 A_{664,1}-5,19 A_{648,6}$

$[\text { Chl b }]_{\frac{m g}{L}}=27,43 A_{648,6}-8,12 A_{664,1}$ 
$[\text { beta }- \text { carotene }]_{\frac{m g}{L}}=\frac{1000 A_{470}-2,13[\text { Chl a }]-97,64[\text { Chl b }]}{209}$

For a clearer presentation of the results, the final pigment concentration was calculated against dried algal biomass and expressed as $\mathrm{mg}$ pigment/g dried algae.

\section{Result and discussion}

In the first stage, experiments were carried out with the change of the microwave power. Microwave treatment was performed for 4 hours / day on days 2, 3, 4 and 5 with 5, 10 and $20 \mathrm{~W}$ microwave power (for the $25 \mathrm{~mL}$ serpentine, the SAR values are : 200, 400 and 800 $\mathrm{W} / \mathrm{kg}$ respectively). Cultures were monitored at all times, and the cell density was read daily. The obtained values (cell number and total dry algae) are shown in Table 1.

From the analysis of the data presented in Table 1 it can be seen that the small microwave powers ( 5 and $10 \mathrm{~W}$ ) have a favorable influence on the number of cells and the total quantity of dried dry algae, while at the power of $20 \mathrm{~W}$ both the number of cells and the algae mass obtained is lower than the control sample.

Considering that the power of $10 \mathrm{~W}$ seems to be the best choice, it has been decided to continue experimenting with the use of microwave treatment at a power of $10 \mathrm{~W}$ for just 2 or 3 days (also with a 4-hour treatment duration /day) with stopping algae growth after these days. The results on cell number evolution are shown in Table 1.

Table 1 Experimental data on microwave irradiated microalgae cultures.

\begin{tabular}{|c|c|c|r|r|r|r|}
\hline & \multicolumn{7}{|c|}{ MW power, W / days of irradiation } \\
\cline { 2 - 7 } & Control & $5 / 4$ & $10 / 4$ & $20 / 4$ & $10 / 2$ & $10 / 3$ \\
\hline SAR (W/kg) & 0 & 200 & 400 & 800 & 400 & 400 \\
\hline Time (days) & \multicolumn{7}{|c|}{ Cell number / $10^{7}$} \\
\hline 0 & 0.14 & 0.10 & 0.10 & 0.10 & 0.01 & 0.01 \\
\hline 1 & 0.70 & 0.62 & 0.56 & 0.62 & 0.54 & 0.50 \\
\hline 2 & 1.31 & 1.09 & 1.09 & 1.09 & 0.98 & 1.05 \\
\hline 3 & 3.97 & 2.51 & 3.11 & 3.11 & 2.32 & 1.95 \\
\hline 4 & 7.25 & 5.33 & 7.81 & 5.33 & & 6.56 \\
\hline 5 & 10.64 & 11.65 & 11.14 & 8.00 & & \\
\hline 6 & 14.19 & 14.81 & 15.77 & 11.14 & & \\
\hline 7 & 16.77 & 17.82 & 19.30 & 12.73 & & \\
\hline 8 & 17.82 & 18.92 & 20.46 & 13.02 & & \\
\hline \multicolumn{7}{|c|}{ The final amount of dry algae (g/L) } \\
\hline
\end{tabular}

It was further determined the amount of lipid fraction and the percentage and composition of oil obtained from the microalgal biomass samples. The results obtained for the case of microwaves irradiated at 5, 10 and 20 watts for 4 days are presented in Table 3. 


\section{High Frequency Heating}

Valencia, Spain, September 9-12, 2019

Table 3 Oil and lipid content for microwave irradiated samples at 5, 10 and 20 watts

\begin{tabular}{|l|c|c|c|c|}
\multicolumn{2}{c}{ for 4 days } \\
\hline & \multicolumn{4}{c|}{ MW power, W / days of irradiation } \\
\hline Lipids content $(\% \mathrm{w} / \mathrm{w})$ & Control & $5 / 4$ & $10 / 4$ & $20 / 4$ \\
\hline Oil content $(\% \mathrm{w} / \mathrm{w})$ & 25.03 & 29.12 & 29.42 & 30.44 \\
\hline Carotenoid content $(\mathrm{mg} / \mathrm{g})$ & 10.15 & 11.40 & 13.80 & 12.35 \\
\hline
\end{tabular}

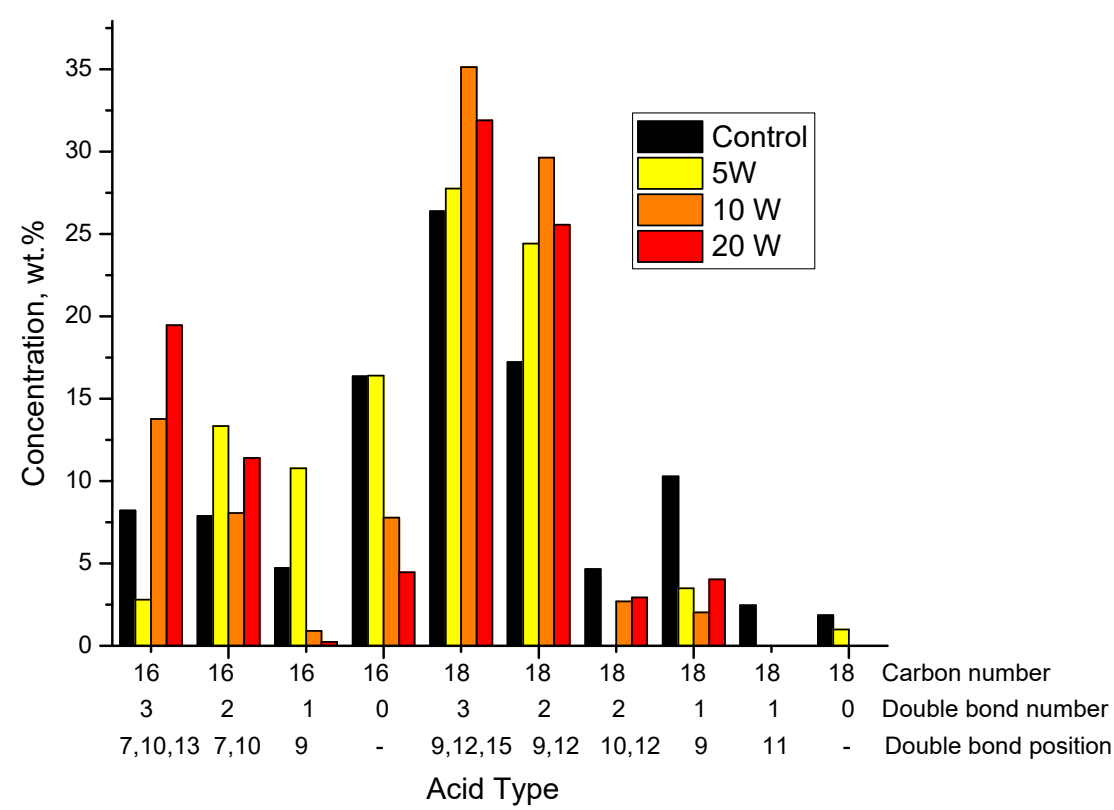

Fig.2. Fatty acid distribution of oil extracted from algae grown for 8 days microwave irradiated at 5, 10 and 20 watts for 4 days.

From the analysis of the data presented in Table 3 and figure 2, it can be noticed an increase in the microalgal biomass oil concentration in all microwave-treated samples. A significant increase is observed in the sample treated with a power of $10 \mathrm{~W}$. As for the distribution of fatty acids the most significant increases are seen in polyunsaturated acids: 16: $3,18: 3$ and 18:2. These increases are particularly noticeable for the $10 \mathrm{~W}$ power. Acids whose concentrations decreases are those with low unsaturation: 16: 0, 18: 1 and 18: 0 .

The carotenoid concentration has also increased with microwave treatment. The best value is also obtained at a $10 \mathrm{~W}$ irradiation.

In order to determine the cell growth period in which the modification of the fatty acid structure occurs, we compared the analysis of treated samples with a microwave power of $10 \mathrm{~W}$ (4 hours / day) for 2 days, 3 days and 4 days respectively for the control sample. The results are shown in table 4 and figure 3. 
Table 4 Oil and lipid content for microwave irradiated samples at 10 watts for 2,3 and 4 days

\begin{tabular}{|l|c|c|c|c|}
\hline & \multicolumn{5}{|c|}{ MW power, W / irradiation days / } \\
& \multicolumn{4}{|c|}{ growing days } \\
\hline & Control & $10 / 4 / 8$ & $10 / 3 / 4$ & $10 / 2 / 3$ \\
\hline Lipids content $(\% \mathrm{w} / \mathrm{w})$ & 25.03 & 29.42 & 21.42 & 19.42 \\
\hline Oil content $(\% \mathrm{w} / \mathrm{w})$ & 10.15 & 13.80 & 7.32 & 5.52 \\
\hline
\end{tabular}

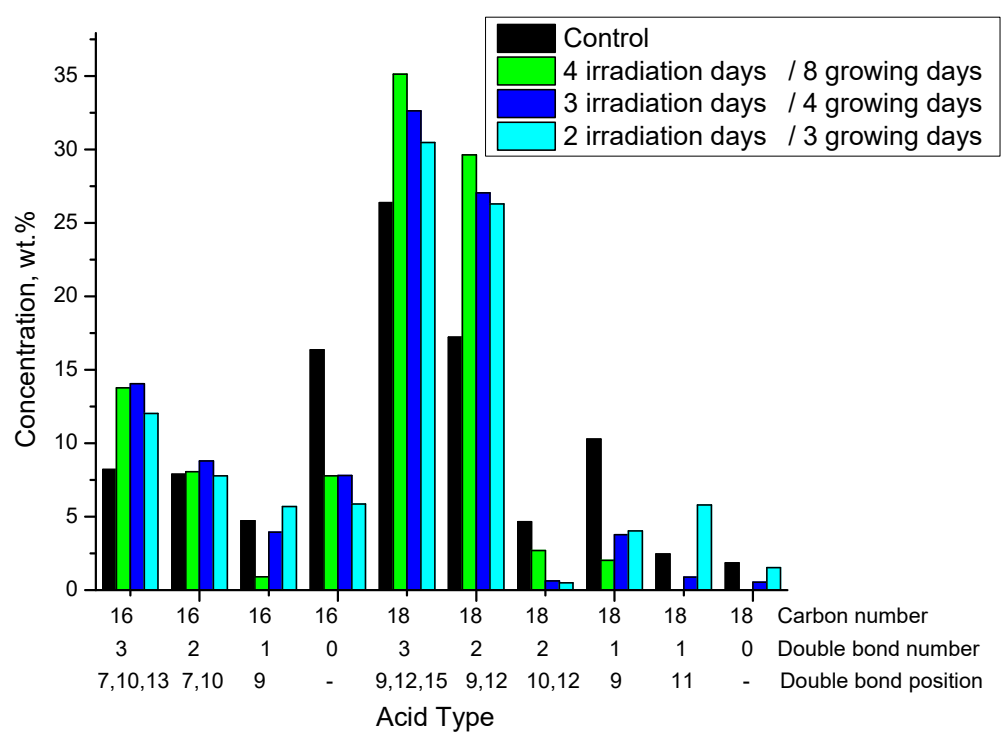

Fig.3. Fatty acid distribution of oil extracted from algae grown under a microwave irradiation of $10 \mathrm{~W}$ for 2,3 or 4 days.

By analyzing the data obtained, a progressive increase in polyunsaturated fatty acid content (16:3, 18:3 and 18:2) can be observed. Growth is very strong after the second day of microwave irradiation and continues on day three and fourth, but with a slower growth rate. Similarly, decreasing the concentration of saturated acids (16:0 and 18:0) or monounsaturated (18:1) is very important after 2 days of microwave irradiation and then the decrease is much lower.

\section{Conclusion}

$\checkmark \quad$ The growth of microalgae of the Nannochloris sp type is influenced by the applied microwave treatment;

$\checkmark$ Growth of the algae was carried out in a Zarrouk growth medium containing the algae through a microwave heated serpentine and through the light irradiated photobiorector;

$\checkmark$ Microwave treatment was performed starting with the next day of growth, for 4 hours / day, with different powers; 
$\checkmark$ Thus, the best microwave treatment condition was obtained which was adequate at a power of $10 \mathrm{~W}$ (SAR $400 \mathrm{~W} / \mathrm{kg})$;

$\checkmark \quad$ Under these conditions an increase in algal mass from 3.03 to $3.35 \mathrm{~g} / \mathrm{L}$, an increase in oil content from 10.15 to $13.8 \%$, but especially a significant increase in the content of polyunsaturated fatty acids (18:3,18:2 and 16:3) and in the concentration of carotenoids from 3.03 to $4.12 \mathrm{mg} / \mathrm{g}$;

$\checkmark$ The use of microwave treatment for just 2 or 3 days showed that the change in the composition of the algal oil begins even after the first day of treatment and continues at a lower rate even after days 2,3 or 4 of treatment.

\section{Acknowledgement}

The authors acknowledge the financial support received from the Competitiveness Operational Programme 2014-2020, Action 1.1.4: Attracting high-level personnel from abroad in order to enhance the RD capacity, project: P_37_471, „Ultrasonic/Microwave Nonconventional Techniques as new tools for nonchemical and chemical processes", financed by contract: 47/05.09.2016

\section{References}

1. Gong, M. and A. Bassi, Carotenoids from microalgae: A review of recent developments. Biotechnology Advances, 2016. 34(8): p. 1396-1412.

2. Juneja, A., R. Ceballos, and G. Murthy, Effects of Environmental Factors and Nutrient Availability on the Biochemical Composition of Algae for Biofuels Production: A Review. Energies, 2013. 6(9): p. 4607-4638.

3. Adeniyi, O.M., U. Azimov, and A. Burluka, Algae biofuel: Current status and future applications. Renewable and Sustainable Energy Reviews, 2018. 90: p. 316-335.

4. Hamid, M.A.K. and S.S. Badour, The Effects of Microwaves on Green Algae. Journal of Microwave Power, 1973. 8(3): p. 268-273.

5. Pakhomov, A.G., et al., Current state and implications of research on biological effects of millimeter waves: A review of the literature. Bioelectromagnetics, 1998. 19(7): p. 393-413.

6. Popescu, A., et al., Microwaves bioeffects on microalgae growth, in 15th International Conference on Microwave and High Frequency Heating AMPERE 2015. 2015: Krakow, Poland.

7. Oancea, F., et al., Nannochloris sp. stain for obtainment of bio-based aviation fuel. 2015.

8. Thoma cell counting chamber. 12.06.2019]; Available from: http://insilico.ehu.es/counting_chamber/thoma.php.

9. Galan, A.M., et al., Development of a new method for determination of the oil content from microalgae lipid fraction. Revista de Chimie, 2017. 68(4): p. 671674.

10. Lichtenthaler, H.K. and C. Buschmann, Chlorophylls and Carotenoids: Measurement and Characterization by UV-VIS Spectroscopy. Current Protocols in Food Analytical Chemistry, 2001. 1(1): p. F4.3.1-F4.3.8. 